\title{
Effect of cardiopulmonary bypass reoxygenation on myocardial dysfunction following pediatric tetralogy of Fallot repair
}

Ji-nong Yang ${ }^{1 \dagger}$, Xiao-ming Zhang ${ }^{1 \dagger}$, Lu-yao Ma², Zhan-jie Lu ${ }^{3}$, Si-qiang Zheng ${ }^{4}$, Al-Wajih Hamzah², Yong-feng Shao ${ }^{2^{*}}$, Hong Liu ${ }^{2,4^{*}+}$ and Gao-li Liu ${ }^{1^{*}}$

\begin{abstract}
Background: Little is known regarding the effect of cardiopulmonary bypass (CPB) reoxygenation on cardiac function following tetralogy of Fallot repair. We hypothesized that hyperoxic reoxygenation would be more strongly associated with myocardial dysfunction in children with tetralogy of Fallot.

Methods: We investigated the association of perfusate oxygenation (PpO2) associated with myocardial dysfunction among children aged 6-72 months who underwent complete repair of tetralogy of Fallot in 2012-2018. Patients were divided into two groups: lower PpO2 group $(\leq 250 \mathrm{mmHg}$ ) and higher PpO2 (>250 mmHg) group based on the highest value of $\mathrm{PpO} 2$ during aortic occlusion. The odd ratio (ORs) and 95\% confidence intervals (Cls) were estimated by logistic regression models.

Results: This study included 163 patients perfused with lower $\mathrm{PpO} 2$ and 213 with higher $\mathrm{PpO} 2$, with median age at surgery 23.3 (interquartile range [IQR] 12.5-39.4) months, 164 female (43.6\%), and median body mass index 15.59 (IQR 14.3-16.9) kg/m². After adjustment for baseline, clinical and procedural variables, patients with higher PpO2 were associated with higher risk of myocardial dysfunction than those with lower PpO2 (OR 1.770; 95\% Cl 1.040-3.012, $P=0.035$ ). Higher PpO2, lower SpO2, lower pulmonary annular Z-score, and longer CPB time were independent risk factors for myocardial dysfunction.
\end{abstract}

Conclusions: Association exists between higher $\mathrm{PpO} 2$ and myocardial dysfunction risk in patients with tetralogy of Fallot, highlighting the modulation of reoxygenation during aortic occlusion to reduce cardiovascular damage following tetralogy of Fallot repair.

Trial registration: Clinical Trials. gov number NCT03568357. June 26, 2018

Keywords: Hypoxia, Reoxygenation injury, Cardiopulmonary bypass, Tetralogy of Fallot, Perfusate oxygenation

*Correspondence: yfshaojph@sina.com; dr.hongliu@foxmail.com; dr.liumd@aliyun.com

${ }^{\dagger} \mathrm{Ji}$-nong Yang, Xiao-ming Zhang, and Hong Liu contributed equally to this work

${ }^{1}$ Department of Cardiovascular Surgery, The Affiliated Hospital of Qingdao University, Qingdao, People's Republic of China 266000

${ }^{2}$ Department of Cardiovascular Surgery, The First Affiliated Hospital of Nanjing Medical University, Nanjing 210038, People's Republic of China Full list of author information is available at the end of the article

\section{Background}

Repair of cyanotic tetralogy of Fallot is increasingly performed in young infants and children [1, 2]. Despite technical improvements, myocardial dysfunction is still challenging that might be mainly attributable in part to chronic hypoxia-reoxygenation injury, which may occur at initiation or during the entire period of cardiopulmonary bypass $(\mathrm{CPB})[3-5]$. 
Previous researches have suggested that reoxygenation injury since the onset of hyperoxic supply during $\mathrm{CPB}$ would lead to oxide free radical production, lipid peroxidation, and impaired post-bypass contractility, which contributed to severe impairment of functional recovery and myocardial antioxidant reserve capacity after operations $[6,7]$. Fortunately, this reoxygenation injury has been attenuated in both animal model and clinical setting by lowing reoxygenation level during initiation of $\mathrm{CPB}$ [8]. However, little is known whether high perfusate oxygenation (PpO2) during aortic occlusion is associated with higher risk of myocardial dysfunction following tetralogy of Fallot repair $[9,10]$.

The primary objective was to estimate the association of $\mathrm{PpO} 2$ during aortic occlusion and myocardial dysfunction following tetralogy of Fallot repair overall, by disease-specific pathologies. The secondary objective was to identify the independent risk factors of developing myocardial dysfunction.

\section{Methods}

\section{Study design and population}

This is a retrospective cohort analysis of patients with tetralogy of Fallot between March 2012 and December 2018 at Teda Cardiovascular Hospital. Consecutive patients were included if they underwent complete repair of tetralogy of Fallot with $\mathrm{CPB}$ at 6-72 months. We excluded patients who had received extracorporeal membrane oxygenation, intra-aortic balloon pump, ventricular assist device, mechanical ventilatory support, or renal replacement therapy before this current surgery. Additional exclusion criteria were incomplete $\mathrm{PpO} 2$ records and missing outcome data for identification of postoperative myocardial dysfunction.

The Institutional Review Board of Teda Cardiovascular Hospital approved the study. This study followed the Declaration of Helsinki and the ethical standards of the responsible committee on human experimentation. Informed consent was waived for this retrospective study. This study was registered with Clinical Trials. gov number NCT03568357.

\section{Study exposure}

Patients were totally heparinized, and an activated clotting time of more than 480 secs was confirmed before the initiation and duration of CPB. Pump flow was settled at approximately $2.8 \mathrm{~L} / \mathrm{min} / \mathrm{m}^{2}$ at the outset of CPB and subsequently adjusted according to patient's core temperature (usually a $20 \%$ decrease for core temperatures between 30 and $34{ }^{\circ} \mathrm{C}$ and an additional $10 \%$ decrease for core temperatures $<30{ }^{\circ} \mathrm{C}$ ). The hemodilution level was decreased to $25-30 \%$ during hypothermic $\mathrm{CPB}$ according to the routine protocol of our institution [11].
We hypnotized that exposure to hyperoxic $\mathrm{CPB}$ would lead to reoxygenation injury in cyanotic patients, so we used the highest $\mathrm{PpO} 2$ during aortic occlusion for analysis. Patients were divided into two groups: lower $\mathrm{PpO} 2$ group $(<250 \mathrm{mmHg})$ and higher $\mathrm{PpO} 2$ group $(>250 \mathrm{mmHg}$ ). PpO2 was available from online blood gas analyzers and confirmed by an independent manual check of extracorporeal circulation records by blinded trained staff.

\section{Outcome}

Primary outcome was myocardial dysfunction, which was confirmed if any of the following is true:

1. need for higher doses of vasoactive drug to maintain blood pressure in normal range (vasoactive-inotropic score [VIS] of greater than 15 points [12]);

2. decrease in blood pressure $<5$ th percentile for age or systolic blood pressure $<2$ SD below normal for age [13];

3. two of the following: unexplained metabolic acidosis, oliguria, prolonged capillary refill $>5 \mathrm{~s}$, core to peripheral temperature gap $>3{ }^{\circ} \mathrm{C}$ [13]; OR

4. Postoperative use of renal replacement therapy, extracorporeal membrane oxygenation, intra-aortic balloon pump, or ventricular assist device [14].

Myocardial dysfunctions were determined throughout postoperative 7 days, hospital discharge, or death, whichever occurred first. Secondary outcome included inotropic score, ICU stay, mechanical ventilation support time, postoperative stay, and hospital cost, as well as the rate of postoperative acute lung injury [15] and systemic inflammatory response syndrome [16].

\section{Study covariates}

Baseline clinical characteristics included age at surgery, sex, body mass index (BMI), hematocrit, percutaneous saturation $\left(\mathrm{SpO}_{2}\right)$, left ventricular end-diastolic volume (LVEDV), and NYHA classification. Disease-specific pathologies included McGoon ratio, pulmonary annular Z-score, and aortopulmonary collateral arteries (APCAS). Procedural characteristics included cardioplegia types, transannular patch, tricuspid valve detachment, CPB time, and intraoperative blood transfusion, as well as immediately postoperative central venous pressure (post-CVP) and transpulmonary gradient (post-TPG).

\section{Statistical analysis}

Continuous data were presented as mean (SD) or median (IQRs) and compared using a t-test or Kruskal-Wallis testing depending on distributed characteristics, and categorical data were reported as percentages (\%) and 
Table 1 Study population and participant characteristics

\begin{tabular}{|c|c|c|c|c|}
\hline & Total & Lower PpO2 (163) & Higher PpO2 (213) & $P$ value \\
\hline \multicolumn{5}{|l|}{ Baseline clinical variables } \\
\hline Age at surgery, month & $23.3(12.5-39.4)$ & $22.77(12.9-39.4)$ & $24.60(12.4-38.8)$ & 0.975 \\
\hline Sex, $\%$ & & & & $<0.001$ \\
\hline Female & $164(43.6 \%)$ & $55(33.7 \%)$ & $109(51.2 \%)$ & \\
\hline Male & $212(56.4 \%)$ & $108(66.3 \%)$ & $104(48.8 \%)$ & \\
\hline Body mass index, $\%$ & $15.59(14.3-16.9)$ & $15.60(14.3-16.8)$ & $15.58(14.3-16.8)$ & 0.974 \\
\hline Hematocrit, \% & $41.7(37.4-48.5)$ & $40.70(37.0-47.0)$ & $42.90(38.1-49.6)$ & 0.141 \\
\hline $\mathrm{SpO} 2, \%$ & $84.0(77.7-93.0)$ & $86.00(78.5-95.0)$ & $82.0(77.0-92.0)$ & 0.004 \\
\hline NYHA class & & & & 0.670 \\
\hline$|-| \mid$ & $353(93.9 \%)$ & $152(93.3 \%)$ & $201(94.4 \%)$ & \\
\hline III-IV & $23(6.1 \%)$ & $11(6.8 \%)$ & $12(5.6 \%)$ & \\
\hline LVEDV index, $\mathrm{ml} / \mathrm{m}^{2}$ & $27.02(19.96-35.66)$ & $29.00(22.59-36.88)$ & $25.84(18.84-34.63)$ & 0.014 \\
\hline \multicolumn{5}{|l|}{ Pulmonary annular z-score } \\
\hline$<-4.0, \%$ & $101(26.9 \%)$ & $50(30.7 \%)$ & $51(23.9 \%)$ & 0.048 \\
\hline-2.0 to $-4.0, \%$ & $117(31.1 \%)$ & $40(24.5 \%)$ & 77 (36.2\%) & \\
\hline$>-2.0, \%$ & $158(42.0 \%)$ & $73(44.8 \%)$ & 85 (39.9\%) & \\
\hline \multicolumn{5}{|l|}{ McGoon index } \\
\hline$\leq 1.5, \%$ & $138(37.1 \%)$ & $54(33.5 \%)$ & $84(39.8 \%)$ & 0.215 \\
\hline$>1.5, \%$ & $234(62.9 \%)$ & $107(66.5 \%)$ & $127(60.2 \%)$ & \\
\hline APCAS, $\%$ & & & & 0.828 \\
\hline None-minimal (untreated) & $187(49.9 \%)$ & $84(51.5 \%)$ & $103(48.6 \%)$ & \\
\hline Minor (untreated) & $79(21.1 \%)$ & $34(20.9 \%)$ & $45(21.2 \%)$ & \\
\hline Major (treated) & $109(29.1 \%)$ & $45(27.6 \%)$ & $64(30.2 \%)$ & \\
\hline \multicolumn{5}{|l|}{ Procedural variables } \\
\hline Cardioplegia, \% & & & & 0.500 \\
\hline 4:1 (Buckberg) & $129(34.3 \%)$ & $59(36.2 \%)$ & $70(32.9 \%)$ & \\
\hline 1:4 (del Nido) & $247(65.7 \%)$ & $104(63.8 \%)$ & $143(67.1 \%)$ & \\
\hline Transannular patch, $\%$ & & & & 0.880 \\
\hline Absence & $165(44.0 \%)$ & $71(43.6 \%)$ & $94(44.3 \%)$ & \\
\hline Presence & $210(56.0 \%)$ & $92(56.4 \%)$ & $118(55.7 \%)$ & \\
\hline Tricuspid valve detachment, \% & & & & 0.461 \\
\hline Absence & $304(80.8 \%)$ & $129(79.1 \%)$ & $175(82.2 \%)$ & \\
\hline Presence & $72(19.2 \%)$ & $34(20.9 \%)$ & $38(17.8 \%)$ & \\
\hline Blood transfusion, \% & & & & 0.017 \\
\hline$<10 \mathrm{ml}$ per kg & $60(16.0 \%)$ & $27(16.6 \%)$ & $33(15.5 \%)$ & \\
\hline 10-30 ml per kg & $121(32.2 \%)$ & $56(34.4 \%)$ & $65(30.5 \%)$ & \\
\hline$>30 \mathrm{ml}$ per kg & $195(51.8 \%)$ & $80(49.0 \%)$ & $115(54.0 \%)$ & \\
\hline Post-CVP, \% & & & & 0.530 \\
\hline $5-10 \mathrm{cmH}_{2} \mathrm{O}$ & $274(72.9 \%)$ & $123(75.5 \%)$ & $151(71.0 \%)$ & \\
\hline$<5 \mathrm{cmH}_{2} \mathrm{O}$ & $30(8.0 \%)$ & $13(8.0 \%)$ & $17(7.9 \%)$ & \\
\hline$>10 \mathrm{cmH}_{2} \mathrm{O}$ & $72(19.2 \%)$ & $27(16.5 \%)$ & $45(21.1 \%)$ & \\
\hline Post-TPG, \% & & & & 0.643 \\
\hline$<15 \mathrm{mmHg}$ & $99(26.3 \%)$ & 46 (28.2\%) & 53 (24.9\%) & \\
\hline $15-30 \mathrm{mmHg}$ & $160(42.6 \%)$ & 70 (42.9\%) & $90(42.2 \%)$ & \\
\hline$>30 \mathrm{mmHg}$ & $117(31.1 \%)$ & $47(28.8 \%)$ & 70 (32.9\%) & \\
\hline CPB time, min & 123.5(90.0-158.5) & $116.0(88.5-143.0)$ & $131.0(92.0-169.0)$ & 0.013 \\
\hline
\end{tabular}

Continuous data are presented as median (IQR) and dichotomous data are presented as counts (\%). $\mathrm{PpO} 2=$ perfusate oxygenation; $\mathrm{SpO} 2=$ percutaneous oxyhemoglobin saturation; LVEDV = left ventricular end-diastolic volume; $\mathrm{APCAS}=$ aortopulmonary collateral arteries; $\mathrm{CPB}=$ cardiopulmonary bypass; post$\mathrm{CVP}=$ immediately postoperative central venous pressure; post-TPG $=$ immediately postoperative transpulmonary gradient 
Table 2 Odds ratios for cardiovascular dysfunction by categorical perfusate oxygenation

\begin{tabular}{|c|c|c|}
\hline & Odds ratio $(95 \% \mathrm{Cl})$ & $P$ value \\
\hline Crude model & & 0.032 \\
\hline$\leq 250 \mathrm{mmHg}$ & 1.000 (ref) & \\
\hline$>250 \mathrm{mmHg}$ & $1.753(1.048,2.933)$ & \\
\hline Adjusted for baseline covariates* & & 0.042 \\
\hline$\leq 250 \mathrm{mmHg}$ & 1.000 (ref) & \\
\hline$>250 \mathrm{mmHg}$ & $1.746(1.019,2.991)$ & \\
\hline Adjusted for baseline and clinical covariates ${ }^{\#}$ & & 0.044 \\
\hline$\leq 250 \mathrm{mmHg}$ & 1.000 (ref) & \\
\hline$>250 \mathrm{mmHg}$ & $1.701(1.014,2.855)$ & \\
\hline Adjusted for baseline, clinical and procedural covariates ${ }^{\$}$ & & 0.035 \\
\hline$\leq 250 \mathrm{mmHg}$ & 1.000 (ref) & \\
\hline$>250 \mathrm{mmHg}$ & $1.770(1.040,3.012)$ & \\
\hline
\end{tabular}

compared using $X^{2}$ or Fisher's exact testing. The odd ratio (ORs) and 95\% confidence intervals (CIs) were estimated by logistic regression models. Baseline adjustments included age at surgery, sex, BMI, hematocrit, SpO2, LVEDV, and NYHA classification. Clinical adjustments included McGoon ratio, pulmonary annular Z-score, and APCAS. Procedural adjustments included cardioplegia types, transannular patch, tricuspid valve detachment, $\mathrm{CPB}$ time, intraoperative blood transfusion, post-CVP, and post-TPG.

We conducted stratified risk analyses by diseasespecific characteristics (pulmonary annular Z-score, McGoon ratio, and APCAS). Heterogeneity of these stratified estimates was evaluated using the likelihood ratio test of the interaction terms between $\mathrm{PpO} 2$ and each covariate.

All covariates showing relative strong associations $(P$ value $<0.1$ ) with myocardial dysfunction in univariate analysis were modelled together to investigate independent risk factors of myocardial dysfunction using multivariate logistic regression. All statistical analysis were performed using Stata version 14 (Stata Corp, College Station, TX, USA) and R software (version 3.2.0). P values of less than 0.05 were considered statistically significant.

All methods were carried out in accordance with relevant guidelines and regulations.

\section{Results}

\section{Patient characteristics}

Our study included 163 patients perfused with lower $\mathrm{PpO}_{2}$ and 213 patients with higher $\mathrm{PpO}_{2}$. Regarding baseline, clinical, and procedural characteristics, patients with higher $\mathrm{PpO}_{2}$ had lower proportion of male
$(P<0.0001)$, lower $\mathrm{SpO}_{2}(P=0.004)$, lower LVEDV index $(P=0.014)$, lower pulmonary annular $\mathrm{Z}$-score $(P=0.014)$, larger blood transfusion $(P=0.017)$ and longer $C P B$ time $(P=0.013)$ (Table 1). Patients perfused with lower and higher $\mathrm{PpO}_{2}$ had similar distribution on age at surgery, hematocrit, BMI, proportion of NYHA class, McGoon ratio, APCAS, cardioplegia types, transannular patch, tricuspid valve detachment, post-CVP, and post-TPG (all $P>0.05)$.

\section{Hospital outcomes}

In relative to those with lower $\mathrm{PpO}_{2}$, patients with higher $\mathrm{PpO}_{2}$ were associated with significantly higher maximum inotropic score, longer ICU stay, longer mechanical ventilation support, longer postoperative stay, and more hospital cost (all $P<0.05)$ in Table 2. Besides, patients with higher $\mathrm{PpO}_{2}$ had higher percentage of acute lung injury ( $30.67 \%$ vs $41.51 \% ; P=0.031)$ and systemic inflammatory response syndrome $(5.37 \%$ vs $11.86 \% ; P=0.038)$ than those with lower $\mathrm{PpO}_{2}$ (online Table 1).

\section{Association of $\mathrm{Ppo} 2$ with myocardial dysfunction}

In unadjusted logistic model, patients with higher $\mathrm{PpO}_{2}$ were associated with higher risk of myocardial dysfunction relative to those with lower $\mathrm{PpO}_{2}$ (OR 1.753; 95\% CI 1.048-2.933; $P=0.032$ ). Adjusted for baseline and clinical variables, there still exists significant association between categorical Ppo2 and risk of myocardial dysfunction (OR 1.701; 95\% CI 1.014-2.855, $P=0.044$ ). After adjustment for baseline, clinical and procedural variables, patients with higher $\mathrm{PpO}_{2}$ were also associated with higher risk of myocardial dysfunction than 


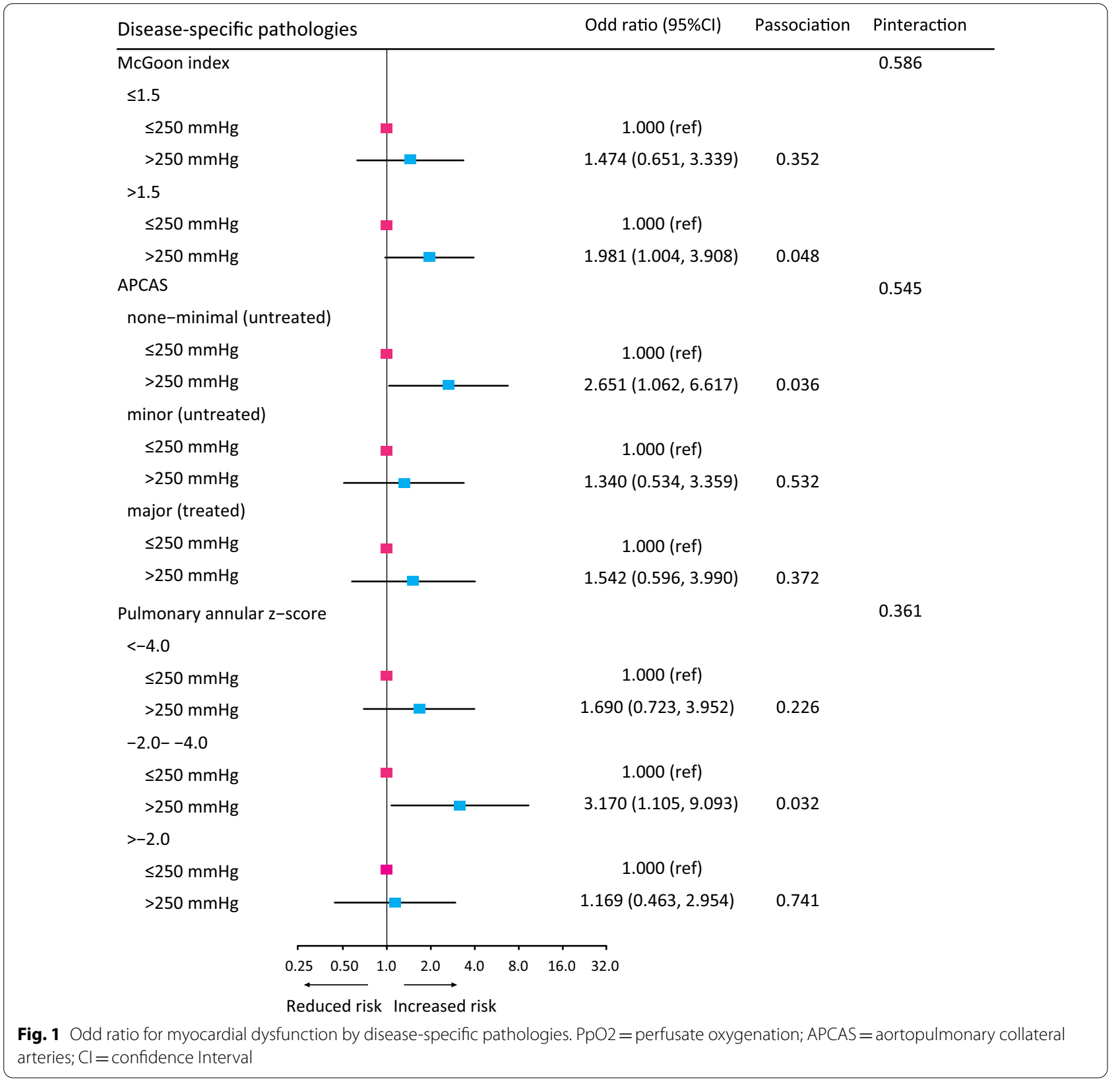

those with lower $\mathrm{PpO}_{2}$ (OR 1.770; 95\% CI 1.040-3.012, $P=0.035$ ) (Table 2).

\section{Subgroup analysis for disease-specific pathologies}

The association between $\mathrm{PpO}_{2}$ and risk of myocardial dysfunction by disease-specific pathologies were summarized in Fig. 1. Despite no statistical evidence for interaction (all $\mathrm{P}$ interaction $>0.05$ ), there was some indications that patients perfused with higher $\mathrm{PpO}_{2}$ were associated with a trend towards increased risk of myocardial dysfunction compared with those with lower $\mathrm{PpO}_{2}$ in disease-specific subgroups.

\section{Independent risk factors of myocardial dysfunction}

All significant variables $(P<0.10)$ in the univariable analysis were entered into the multivariable logistic regression model. The multivariate analysis indicated that categorical $\mathrm{PpO}_{2}$, lower $\mathrm{SpO}_{2}$, lower pulmonary annular Z-score, and longer $\mathrm{CPB}$ time were independent risk factors for myocardial dysfunction (Table 3). 
Table 3 Multivariable logistic regression analysis for cardiovascular dysfunction risk

\begin{tabular}{|c|c|c|}
\hline & Odds ratio $(95 \% \mathrm{Cl})$ & $P$ value \\
\hline \multicolumn{3}{|l|}{ Categorical $\mathrm{PpO}_{2}, \%$} \\
\hline Lower PpO2 & 1.000 (ref) & \\
\hline Higher PpO2 & $1.858(1.078,3.202)$ & 0.026 \\
\hline \multicolumn{3}{|l|}{ Clinical covariates } \\
\hline Sex $\%$ & & 0.667 \\
\hline Female & 1.000 (ref) & \\
\hline Male & $0.886(0.510,1.539)$ & \\
\hline $\mathrm{SpO}_{2}$ (per \% increase) & $0.954(0.927,0.983)$ & 0.002 \\
\hline LVEDV index, $\mathrm{ml} / \mathrm{m}^{2}$ & $1.005(0.981,1.030)$ & 0.668 \\
\hline \multicolumn{3}{|l|}{ Pulmonary annular Z-score, \% } \\
\hline$<-4.0$ & 1.000 (ref) & \\
\hline-2.0 to -4.0 & $0.747(0.395,1.415)$ & 0.372 \\
\hline$>-2.0$ & $0.451(0.220,0.924)$ & 0.030 \\
\hline McGoon index, \% & & 0.341 \\
\hline$\leq 1.5$ & 1.000 (ref) & \\
\hline$>1.5$ & $1.325(0.742,2.366)$ & \\
\hline \multicolumn{3}{|l|}{ Blood transfusion, \% } \\
\hline None (<10 ml per kg) & 1.000 (ref) & \\
\hline Minor (10-30 ml per kg) & $1.011(0.481,2.125)$ & 0.978 \\
\hline Major (> 30 ml per kg) & $1.015(0.455,2.264)$ & 0.972 \\
\hline CPB time (per min increase) & $1.009(1.004,1.014)$ & 0.0002 \\
\hline
\end{tabular}

$\mathrm{PpO}_{2}=$ perfusate oxygenation; $\mathrm{SpO}_{2}=$ percutaneous oxyhemoglobin saturation; $\mathrm{LVEDV}=$ left ventricular end-diastolic volume; $\mathrm{CPB}=$ cardiopulmonary bypass. $\mathrm{Cl}=$ confidence interval

\section{Discussion}

Our findings show that significant association of higher $\mathrm{PpO} 2$ during aortic occlusion with myocardial dysfunction risk after adjustment for potential variables. There were some indications that patients perfused with higher $\mathrm{PpO}_{2}$ were associated with a trend towards increased risk of myocardial dysfunction compared with those with lower $\mathrm{PpO}_{2}$ in disease-specific subgroups. Higher $\mathrm{PpO} 2$, lower $\mathrm{SpO} 2$, lower pulmonary annular Z-score, and longer CPB time were independent risk factors for myocardial dysfunction.

\section{Interpretation and implications}

Different from previous studies regarding the reoxygenation during initiation of $\mathrm{CPB}[5-8,17]$, we have an exclusive focus on the reoxygenation during aortic occlusion. Our findings showed that patients perfused with higher $\mathrm{PpO} 2$ were associated with higher risk of myocardial dysfunction relative to those perfused with lower $\mathrm{PpO} 2 \mathrm{mmHg}$ despite multivariable adjustments for clinical and procedural variables, which is consistent with their previous results, which provided evidence verifying impaired cardiac function and of biochemical parameters closely correlating with poor surgical outcome attributable to reoxygenation injury $[3,4,18]$. Thus, it highlights the therapeutic modalities of reoxygenation not only during initial $\mathrm{CPB}$ but also during aortic occlusion process in the management of oxygenation in tetralogy of Fallot repair [19].

Myocardial dysfunction is multifactorial in etiology, including myocardial depression following bypass, altered cardiovascular loading conditions, and inflammation driving a hypermetabolic state, which particularly associated with procedural factors in addition to patient baseline clinical characteristics [20, 21]. Not surprisingly, our multivariate analysis identified lower $\mathrm{SpO} 2$, lower pulmonary annular Z-score, and longer CPB time were independent risk factors of myocardial dysfunction. Consequently, understanding and accurately estimating perioperative risk by accounting for the intrinsic risk of surgical procedures and patient clinical characteristics will lead to a timely and accurate use of hemodynamic monitoring for a better identification and management of patients as risk for or in a state of myocardial dysfunction $[22,23]$.

It is interesting that the presence of transannular patch did not warrant retention in our multivariable model in light of previous work demonstrating that in patients undergoing tetralogy of Fallot repair transannular patch is associated with increased risk of postoperative low cardiac output syndrome [24]. This is likely due to the fact that the presence of transannular patch was considered as a binary variable in this analysis and the specific RVOT-related procedures (e.g. parietal muscle resection, infundibular outflow patch, valve-sparing surgery, transannular patch, or pulmonary patch) was not considered when predicting myocardial dysfunction in this present study. It is also likely that these infants and children who underwent transannular patch usually had high clinical risk more frequently, such as lower preoperative $\mathrm{SpO} 2$ which was included in the prediction model as an impendent risk factor, than those who did not underwent transannular patch [25].

There are certain limitations to this study. While we used a consensus-based definition for myocardial dysfunction, the selection of threshold of vasoactive-inotropic score is neither uniform nor specific, and we cannot rule out some misclassification. Despite multivariable adjustments for measured factors for this analysis, the residual bias from unmeasured factors and effectmodifying potentials cannot be completely excluded.

\section{Conclusions}

Our findings showed higher Ppo2 during aortic occlusion was associated with risk of myocardial dysfunction, highlighting the modulation of reoxygenation during aortic 
occlusion to reduce cardiovascular damage in patients with tetralogy of Fallot. Also, higher $\mathrm{PpO}$, lower SpO2, lower pulmonary annular Z-score, and longer $\mathrm{CPB}$ time were independent risk factors for myocardial dysfunction. However, the unmeasured factors with confounding and effect-modifying potentials affecting myocardial dysfunction cannot be excluded.

\section{Supplementary Information}

The online version contains supplementary material available at https://doi. org/10.1186/s12872-021-02033-2.

Additional file 1: Online Table 1. Hospital outcome.

\section{Acknowledgements}

Not applicable.

\section{Authors' contributions}

$\mathrm{HL}$ drafted the manuscript, interpreted the patient data and oversaw statistical analysis and data collection. All authors performed data collected and interpreted the patient data. HL performed all statistical analysis. All authors provided blinded interpretation of electrogram analysis as part of the study procedures. YS provided overall supervision and drafted the original concept of the study. All authors read and approved the final manuscript.

\section{Funding}

This work was supported by the National Natural Science Foundation of China (82000305).

\section{Availability of data and materials}

The datasets used and/or analysed during the current study are available from the corresponding author on reasonable request.

\section{Declarations}

\section{Ethics approval and consent to participate}

This study was approved by the Institutional Review Board of Teda Cardiovascular Hospital. Informed consent was waived for this retrospective study.

\section{Consent for publication}

Not applicable.

\section{Competing interests}

The authors have no conflicts of interest to declare.

\section{Author details}

${ }^{1}$ Department of Cardiovascular Surgery, The Affiliated Hospital of Qingdao University, Qingdao, People's Republic of China 266000. ${ }^{2}$ Department of Cardiovascular Surgery, The First Affiliated Hospital of Nanjing Medical University, Nanjing 210038, People's Republic of China. ${ }^{3}$ School of Public Health Management, Nanjing University of Chinese Medicine, Nanjing 210029, People's Republic of China. ${ }^{4}$ Department of Cardiovascular Surgery, Teda Cardiovascular Hospital, Chinese Academy of Medical Sciences \& Peking Union Medical College, Beijing 100730, People's Republic of China.

Received: 23 October 2020 Accepted: 26 March 2021

Published online: 26 April 2021

\section{References}

1. Pitz C, Webb GD, Redington AN. Tetralogy of Fallot. Lancet. 2009;374(9699):1462-71.

2. Al Habib HF, Jacobs JP, Mavroudis C, Tchervenkov Cl, O'Brien SM, Mohammadi S, et al. Contemporary patterns of management of tetralogy of
Fallot: data from the Society of Thoracic Surgeons Database. Ann Thorac Surg. 2010;90(3):813-20.

3. Bulutcu FS, Bayindir O, Polat B, Yalcin Y, Özbek U, Cakali E. Does normoxemic cardiopulmonary bypass prevent myocardial reoxygenation injury in cyanotic children? J Cardiothorac Vasc Anesth. 2002;16(3):330-3.

4. Allen BS, Rahman S, llbawi MN, Kronon M, Bolling KS, Halldorsson AO, et al. Detrimental effects of cardiopulmonary bypass in cyanotic infants: preventing the reoxygenation injury. Ann Thorac Surg. 1997;64(5):1381-8.

5. Caputo M, Mokhtari A, Rogers CA, Panayiotou N, Chen Q, Ghorbel MT, et al. The effects of normoxic versus hyperoxic cardiopulmonary bypass on oxidative stress and inflammatory response in cyanotic pediatric patients undergoing open cardiac surgery: a randomized controlled trial. J Thorac Cardiovasc Surg. 2009;138(1):206-14.

6. Ghorbel MT, Mokhtari A, Sheikh M, Angelini GD, Caputo M. Controlled reoxygenation cardiopulmonary bypass is associated with reduced transcriptomic changes in cyanotic tetralogy of Fallot patients undergoing surgery. Physiol Genom. 2012;44(22):1098-106.

7. Matheis G, Abdel-Rahman U, Braun S, Wimmer-Greinecker G, Esmaili A, Seitz $\mathrm{U}$, et al. Uncontrolled reoxygenation by initiating cardiopulmonary bypass is associated with higher protein $\mathrm{S} 100$ in cyanotic versus acyanotic patients. Thorac Cardiovasc Surg. 2000;48(5):263-8.

8. Babu B, Bhat S, Prabuswamy HP, Kamalapurkar G, Kumar HV, Libu GK, et al. Controlling oxygenation during initiation of cardiopulmonary bypass: can it improve immediate postoperative outcomes in cyanotic children undergoing cardiac surgery? A prospective randomized study. World J Pediatr Congenit Heart Surg. 2012;3(3):310-6.

9. Yuan X, Lee JW, Bowser JL, Neudecker V, Sridhar S, Eltzschig HK. Targeting hypoxia signaling for perioperative organ injury. Anesth Analg. 2018;126(1):308-21.

10. Medikonda R, Ong CS, Wadia R, Goswami D, Schwartz J, Wolff L, et al. Trends and updates on cardiopulmonary bypass setup in pediatric cardiac surgery. J Cardiothorac Vasc Anesth. 2019;33(10):2804-13.

11. Liu H, Zheng SQ, Qian SC, He HH, Xue JR. Haematocrit differences modify the association of cardiopulmonary bypass reoxygenation with acute kidney injury after paediatric Tetralogy of Fallot repair. Perfusion. 2019 https://doi.org/10.1177/0267659119871777.

12. Gaies MG, Gurney JG, Yen AH, Napoli ML, Gajarski RJ, Ohye RG, et al. Vasoactive-inotropic score as a predictor of morbidity and mortality in infants after cardiopulmonary bypass. Pediatr Crit Care Med. 2010;11(2):234-8.

13. Goldstein B, Giroir B, Randolph A. International Consensus Conference on Pediatric Sepsis. International pediatric sepsis consensus conference: definitions for sepsis and organ dysfunction in pediatrics. Pediatr Crit Care Med. 2005;6(1):2-8.

14. Singer M, Deutschman CS, Seymour CW, et al. The third international consensus definitions for sepsis and septic shock (sepsis-3). JAMA. 2016:315(8):801-10.

15. Liu H, Zheng SQ, Zeng ZH, Liu ZG, Liu XC, Shao YF. Association between perfusate oxygenation and acute lung injury in tetralogy of fallot surgery. Shock. 2019. https://doi.org/10.1097/SHK.0000000000001475.

16. Kaukonen KM, Bailey M, Pilcher D, Cooper DJ, Bellomo R. Systemic inflammatory response syndrome criteria in defining severe sepsis. N Engl J Med. 2015;372(17):1629-38.

17. Morita K. Surgical reoxygenation injury of the myocardium in cyanotic patients: clinical relevance and therapeutic strategies by normoxic management during cardiopulmonary bypass. Gen Thorac Cardiovasc Surg. 2012;60(9):549-56.

18. Morita K. Invited commentary: surgical reoxygenation injury in myocardium of patients with cyanosis: how is it clinically important? World J Pediatr Congenit Heart Surg. 2012;3(3):317-20.

19. Murphy GS, Hessel EA 2nd, Groom RC. Optimal perfusion during cardiopulmonary bypass: an evidence-based approach. Anesth Analg. 2009;108(5):1394-417.

20. Epting CL, McBride ME, Wald EL, Costello JM. Pathophysiology of post-operative low cardiac output syndrome. Curr Vasc Pharmacol. 2016;14(1):14-23.

21. Bautista-Hernandez V, Karamanlidis G, McCully JD, Del Nido PJ. Cellular and molecular mechanisms of low cardiac output syndrome after pediatric cardiac surgery. Curr Vasc Pharmacol. 2016;14(1):5-13.

22. Chandler HK, Kirsch R. Management of the low cardiac output syndrome following surgery for congenital heart disease. Curr Cardiol Rev. 2016:12(2):107-11. 
23. Nordness MJ, Westrick AC, Chen H, Clay MA. Identification of low cardiac output syndrome at the bedside: a pediatric cardiac intensive care unit survey. Crit Care Nurse. 2019;39(2):e1-7.

24. Khan I, Tufail Z, Afridi S, Iqbal M, Khan T, Waheed A. Surgery for tetralogy of fallot in adults: early outcomes. Braz J Cardiovasc Surg. 2016;31(4):300-3.

25. McKenzie ED, Maskatia SA, Mery C. Surgical management of tetralogy of Fallot: in defense of the infundibulum. Semin Thorac Cardiovasc Surg. 2013;25(3):206-12.

\section{Publisher's Note}

Springer Nature remains neutral with regard to jurisdictional claims in published maps and institutional affiliations.
Ready to submit your research? Choose BMC and benefit from:

- fast, convenient online submission

- thorough peer review by experienced researchers in your field

- rapid publication on acceptance

- support for research data, including large and complex data types

- gold Open Access which fosters wider collaboration and increased citations

- maximum visibility for your research: over 100M website views per year

At BMC, research is always in progress.

Learn more biomedcentral.com/submissions 